\title{
THE ROLE OF IT SERVICE MANAGEMENT IN GREEN IT
}

\author{
Aileen Cater-Steel \\ School of Information Systems, University of Southern Queensland \\ Toowoomba, Australia \\ Wui-Gee Tan \\ School of Information Systems, University of Southern Queensland \\ Toowoomba, Australia
}

\begin{abstract}
Societies and governments are becoming increasingly concerned about the impact of the expanding use of IT equipment on the environment, especially in terms of energy efficiency, emission reduction and toxic waste. The objective of this article is to explore the relationship between IT Service Management (ITSM) and Green IT. To achieve this objective, the leading best practice framework for ITSM is evaluated to explore the depth and breadth of Green IT guidance provided in the ITIL resources. The analysis of the ITIL books clearly demonstrates that ITIL provides limited guidance to support Green IT programs and confirms the view that Green IT and ITSM share common goals, such as operational efficiencies and metrics-based improvements. In the second phase of the research, results of a recent survey of IT Service Managers in Australia were analysed to gauge the extent of Green IT awareness and implementation. The extent to which Green IT policies and procedures have been implemented varied substantially across the 65 organisations surveyed. The survey results indicate that most of the IT Service Managers have implemented a Green IT Policy and are aware of the importance of controlling IT waste disposal and improving energy efficiency. Based on the discussion, recommendations are made to CIOs, IT Service Managers and ITIL authors to continue to raise awareness of Green IT and to recognise that best practice in Green IT is evolving and needs to be distilled and articulated in ITIL publications.
\end{abstract}

\section{INTRODUCTION}

It is recognised that the global ICT industry has a significant impact on the environment with estimates that it contributes carbon dioxide emissions equivalent to the aviation industry (ACS 2007; Gartner 2007). Power consumption is also a concern: large organisations spend between four and ten percent of their total ICT budgets on energy and this proportion is expected to quadruple by 2012 due to the twin factors of power-hungry hardware and rising energy costs (Gershon 2008). Organisations are urged to consider their carbon footprint and redesign business processes to reduce carbon emissions (Ghose et al. 2009).

IT Operations and Services form a vital subset of the ICT industry. Personnel who provide IT Service Management (ITSM) include in-house ICT departments delivering ICT services within organizations as well as vendor service providers of out-sourced services. ITSM has an important role to play in 
greening IT as it controls ICT infrastructure which consumes vast quantities of energy in manufacture of components as well as in the ongoing operation of ICT systems (Erek et al. 2009; Firth 2008). ITSM is also responsible for the disposal of upgraded ICT equipment which contributes significant quantities of toxic waste to the environment (Blanke 2009).

ITSM standards such as the IT Infrastructure Library (ITIL) are of increasing importance to IT departments in organisations around the globe. The ITIL framework is provided in a set of comprehensive and coherent publications providing descriptive guidance on IT service management. The first version of ITIL was developed by a British Government agency in the 1980s to promote efficient and cost-effective IT operations within government controlled computing centres. The framework is currently administered by the UK's Office of Government Commerce (OGC). Although the actual number of organisations adopting ITIL is not known, there are many indicators of its growing popularity and adoption. For example, there are more than 50 national chapters of the IT Service Management Forum (itSMF) with more than 40,000 members worldwide (itSMFI 2010); itSMF conferences report robust attendances each year; and the demand for ITIL-qualified staff is increasing, accompanied by an increase in the number of ITIL Foundation certificates granted to individuals. Since the international standard for IT service management (ISO/IEC 20000) based on ITIL was published in 2005, over 484 organisations in at least 43 countries have achieved certification to the standard (itSMF 2009).

According to Murugesan (2008), Green IT refers to the study and practice of designing, manufacturing, using, and disposing of computers, servers, and associated subsystems efficiently and effectively with minimal or no impact on the environment. He states the objective of Green IT is 'to achieve economic viability and improved system performance and use, while abiding by our social and ethical responsibilities' (p. 26).

Many of the Green IT issues and activities identified by Watson et al. (2007) and Murugesan (2008) fall squarely in the domain of ITSM, in particular:

- purchase of energy-efficient computing equipment;

- power management to reduce energy consumption of data centres and replacement of personal computers with energy efficient thin clients;

- consolidation and use of virtualisation software to run multiple operating systems on one server; and

- $\quad$ recycling and responsible waste disposal of obsolete computing equipment.

The objective of this paper is to explore the relationship between ITSM and Green IT. To achieve this objective, the leading best practice framework for ITSM is analysed to explore the depth and breadth of Green IT guidance provided in the ITIL resources. A pragmatic approach is taken to classify the knowledge promoted to ITSM practitioners based on the ITIL publications (Alavi \& Leidner 2001). As well, results of a recent survey of IT Service Managers in Australia are analysed to gauge the extent of Green IT awareness and implementation at their organisations. The literature review briefly summarises academic research, practitioner reports and industry standards. After the methodology is described, the results of the analysis of the latest ITIL guidelines are presented and used to frame the survey questions. Following the reporting of the survey results, the discussion links the findings to previous research and is followed by the conclusions, recommendations, limitations and directions for further research.

\section{RESEARCH TO DATE}

Back in 1987, Benbasat et al. highlighted that constant technological change and innovation resulted in IS researchers 'trailing behind practitioners' (p. 370). Today, Green IT seems to be one area where 
practice is leading academia and researchers need to study the innovations put in place by practitioners. Therefore, after a review of the academic literature, recent practitioner publications relating to Green IT in the area of ITSM are reported, followed by a summary of government initiatives and standards. From this review of the literature, a preliminary theoretical framework is proposed.

\section{Academic Research}

To date, apart from Brown et al. (2005), Chen et al. (2008), Maruster et al. (2008), Huang (2009), Ghose et al. (2009), Kuo and Dick (2009) and Molla et al. (2009) there have been few studies on Green IT reported in top tier Information Systems journals. This is probably a reflection on the time lag inherent in the academic publication cycle. On the other hand, Information Systems conferences such as ICIS, ACIS, PACIS, AMCIS and HICCS have reported increasing research activity in Green IT topics.

Based on their study of four cases, Sarkar and Young (2009) attempted to explore the main economic, socio-political, and institutional influences that motivate top management attitudes towards the implementation of a Green IT policy. Their findings suggest that ultimately attitudes will only be transformed into action when a sound cost model exists that highlights the relationship between potential cost savings and Green IT initiatives, supplemented by clearly designed long-term awareness programs surrounding the issue.

Schmidt et al. (2009) noted that while the concepts of corporate social responsibility or sustainability have been applied to other industries, Information Systems (IS) is still lagging in this respect. They developed a sustainable IS management procedural model to provide senior IS managers with a framework for addressing sustainability in their business operation.

Elliott (2007) derived a definition of environmental sustainability of ICT from a review of diverse literature sources. He presents a rationale for IS researchers to contribute to the resolution of the issue and a taxonomy to facilitate the research. Following on from this work, Elliott and Binney (2008) observe that IS research literature to date has provided little assistance to those organisations who are unsure about how, where, and when to respond to imperatives for their ICT applications and practices to become 'Green'. They drew from the literature and the experience of a global ICT services corporation to propose a 'stages of development' framework for corporate capabilities in ICT environmental sustainability.

The integrated information management model (IIM) was developed by Zarnekow et al. (2006) as an adaptation of the Supply Chain Operations Reference (SCOR) model for Information Systems software and service providers. Recently, the IIM model was extended by Erek et al. (2009) to create a lifecycle oriented view on IS services by adding a fourth process (return) to the IIM's three core processes (source, make, deliver). The study conducted by Erek et al. (2009) revealed significant awareness of Green issues in relation to data centres.

Capra and Merlo (2009) also focus on data centres, specifically in regards to energy consumption of software applications. By taking a top-down approach they attempted to pinpoint the original cause that leads to the energy consumption. Capra and Merlo further propose a research roadmap to identify a set of software complexity and quality metrics that can be used to estimate energy consumption and to compare specific software applications.

Applying institutional theory, Butler and Daly (2009) developed a series of theoretical propositions and argue that regardless of whether it is an interest in Green IT or in cost reduction, the concerns of business and IT managers are modulated by regulative, normative, and cultural-cognitive influences in the institutional environment. In a similar vein, a theoretical model was developed and tested by Kuo and Dick (2009) who found that initiatives are more likely to be motivated from a sense of social 
responsibility from empowered employees rather than as a response to external legitimation pressures or pursuit of competitive advantage.

A significant research contribution has been made by Molla and his colleagues. Molla (2008) proposes a model, called the Green IT Adoption Model (GITAM), to facilitate the systematic investigation of Green IT adoption. The model posits that the technological, organisational and environmental contextual variables, dynamic Green IT readiness dimensions and strong order Green IT drivers can predict the intention, breadth and depth of Green IT adoption. Continuing on the theme of Green-IT readiness, Molla et al. (2008) describe the main pillars of a g-readiness framework to help organisations evaluate their readiness for adopting Green IT.

From a comprehensive review of extant literature related to Green IT, Molla (2009) provides a summary of research to date organized into three categories: the 'goal of greenness', the 'locus of greenness', and the 'context of greenness'. Applying his taxonomy to this study, our ITSM focus relates to three of his goals of greenness: e-waste; emission reduction; and energy efficiency. In terms of locus of greenness, we are interested in the IT artefact and the IT department. Three of Molla's dimensions of the context of greenness apply to our study: sourcing; operation; and disposal.

Other disciplines are also showing leadership in tackling the Green IT issue. For example, in the Operations Management field, Walker et al. (2009) focused on sustainable procurement, and Hart (1997) considered business strategies for sustainability.

\section{Practitioner Research and Advice}

In recent years, the ICT practitioner press has produced myriad reports from research firms, consultants and vendors. These reports provide explicit advice to IT managers on Green IT perspectives, for example, the role of IT Management software (Scheerer \& Somashekar 2009); the next wave of Green IT (Knox \& Lull 2009); consulting services (Mines 2008), consolidation and virtualisation (Poniatowski 2009), and cost optimization (Potter 2008). To the authors' knowledge, only three have specifically considered the role of ITIL in relation to Green IT initiatives: Firth (2008), Blanke (2009) and Cherrington and Greenway (2008).

\section{Government Initiatives and International Standards}

In recent years, in response to growing awareness of climate change, a confusing plethora of initiatives, standards and guidelines have been developed to assist organisations achieve environmentally sustainable practices. For example, the international standard ISO 14001 helps organisations to continually improve their environmental performance by identifying and controlling the environmental impact of activities, products or services; and implementing a systematic approach to setting and achieving environmental objectives and targets (ISO 2004). Developed in the United Kingdom by BSI British Standards and co-sponsored by the Carbon Trust and the UK's Department for Environment, Food and Rural Affairs (Defra), BSI PAS 2050 is a publicly available specification for assessing product lifecycle greenhouse gas emissions (BSI 2008). Also relevant to ITSM is the Energy Star international standard for energy efficient office equipment including computers and printers (EPA 2009). Specific to ICT equipment, the Electronic Product Environmental Assessment Tool (EPEAT) helps ICT Managers evaluate, compare and select electronic products based on their environmental attributes (GEC 2006). This system currently covers desktop and laptop computers, thin clients, workstations and computer monitors. In the European Community, the Waste Electrical and Electronic Equipment Directive (WEEE) together with the Directive on the Restriction of the use of certain Hazardous Substances in electrical and electronic equipment (RoHS) became European Law in February 2003. The directives set collection, recycling and recovery targets for all types of electrical goods and impose the responsibility for the disposal of waste electrical and electronic equipment on the manufacturers of such equipment (EC 2008). However, in Australia, ICT managers 
would need to comply with the Hazardous Waste (Regulation of Exports and Imports) Act 1989 only if they are exporting obsolete ICT equipment (COMLAW 2009).

Many Governments are leading by example by enforcing orders or guidelines on their agencies. For example, in the United States, guidelines for ICT procurement by government agencies state that 95 percent of new ICT acquisitions must be compliant with Energy Star or the Federal Energy Management Program, or certified by the EPEAT, contain recycled content, or otherwise be more sustainable than other products. The US Government order also touches on the energy impact of Federal data centres, one of the largest consumers of energy. US Federal agencies must now implement best practices for energy-efficient servers and data centre management including power management policies and double-sided printing. End of life concerns are also included with a requirement for E-recycling and care in the disposition of electronic products (Hoover 2009).

In December 2007, the Australian Government's Information Management Office (AGIMO) issued the 'Environmental Impact Better Practice Checklist' to help agencies reduce the impact of their information and communication technology activities on the environment (AGIMO 2007). The aim of the Checklist, reproduced as Table 1, is to assist agencies in managing the environmental impact of ICT products and services.

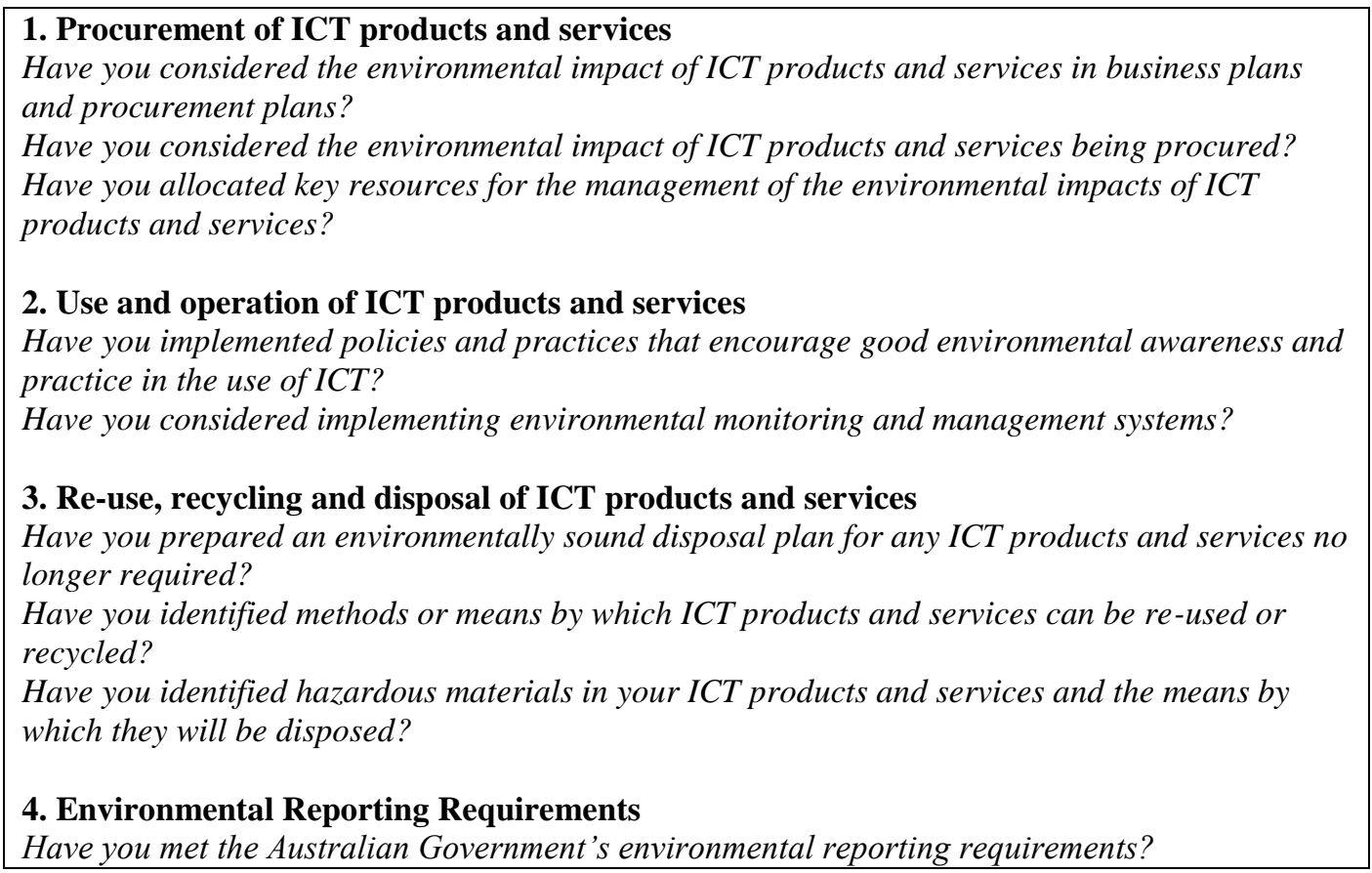

Table 1. Managing the environmental impact of ICT (AGIMO 2007)

Analysis of the AGIMO Checklist reveals that the first three sections are strongly related to ICT infrastructure and as such are the responsibility of ITSM. Although the jurisdiction of the AGIMO model is currently restricted to government agencies, research shows that over time, initiatives instigated by Federal Governments often flow to the private sector. As well as laws and regulations, Governments create norms, actions, or behaviours that people accept as good or take for granted (Scott 2000). 


\section{PRELIMINARY THEORETICAL FRAMEWORK}

Although this research takes a pragmatic approach, it draws on prior research and the AGIMO model to identify four initiatives we believe contribute to Green IT from an ITSM perspective:

- Procurement of power efficient hardware is identified by many researchers, for example Blanke (2009). Erek et al. focus on the 'source' phase of the IS value chain and the need to audit suppliers for conformance to energy efficient standards (2009). Specifically, the use of thin clients in place of PCs is promoted by Velte et al. (2008) and Cole (2003).

- Servers have proliferated in many data centres and as well as drawing resources for power and cooling, occupy valuable space. Server virtualisation offers opportunities to consolidate IT resources (Erek et al. 2009; Velte, Velte \& Elsenpeter 2008).

- Power management of data centres and PCs is acknowledged as an important initiative (Murugesan 2008).

- In view of the toxic chemicals incorporated into IT equipment, disposal is an important challenge. IT managers need to consider decommissioning, recycling or reusing unused or obsolete equipment (Matthews \& Matthews 2003; Saied \& Velaquez 2003).

Figure 1 shows the preliminary theoretical framework.

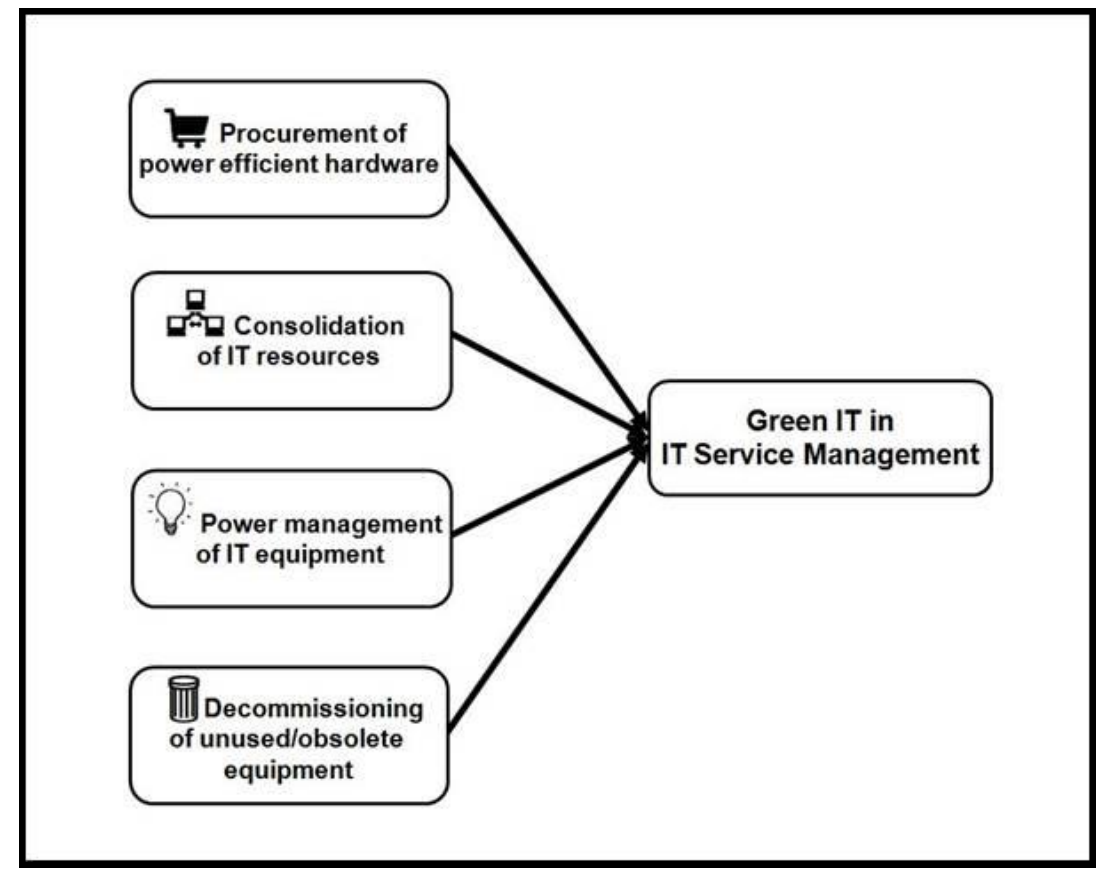

Figure 1. A preliminary framework of initiatives contributing to Green IT Service Management 


\section{METHODOLOGY}

A multi-method two phase approach was adopted for this study. In the first phase, content analysis was used to examine the five ITIL version 3 (ITILv3) reference books to identify the extent to which Green IT principles are included in the ITIL framework. In the process of reviewing the literature on Green IT and ITSM to develop the preliminary model (Figure 1), a list of relevant keywords was compiled. Keywords included: procurement, virtualisation, disposal, decommissioning, retirement, Green IT economics, environmental policy, physical facilities optimization, supplier contract negotiation, Green IT attributes in CMDB, power management, continual evaluation and improvement.

Version 3 of ITIL is presented as a set of five volumes: Service Strategy, Service Design, Service Transition, Service Operation and Continual Service Improvement (OGC 2007a, 2007b, 2007c, 2007d, 2007e). Following Krippendorff's guidelines (2004), these books were read to identify the specific terms and practices relevant to Green IT. The analysis was done manually and systematically with results recorded in a matrix format.

The second phase of the study took the output from the content analysis and operationalised it as survey questions which were distributed to IT Service Managers at the IT Service Management Forum (itSMF) Australian Conference in 2009.

\section{ITIL Content Analysis}

The guidelines in ITIL were considered in terms of their contribution to the four initiatives presented in Figure 1:

- Procurement of power efficient hardware and energy efficient workstations and monitoring suppliers' adherence to Green standards;

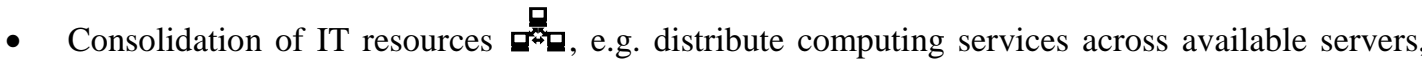
virtualisation to allow multiple system implementations on a single server;

- Power monitoring and management , e.g. automatic shutdown/power-up processes;

- Decommissioning of unused/redundant systems 岁.

During the content analysis of the ITIL books a matrix was developed which listed the ITIL volume (1-5), process or function, relevant initiative, pertinent text and section reference.

The following Tables (2-6) present excerpts from specific sections for each relevant ITSM process in

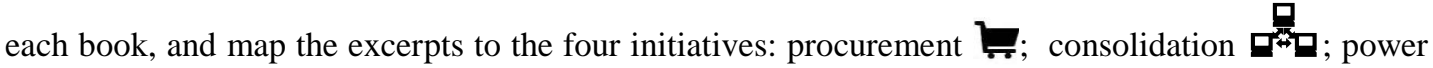
efficiency ; disposal 而

Financial Management and Demand Management address service economics in the Service Strategy stage of the ITILv3 lifecycle and as shown in Table 2 are particularly relevant to Green IT. All IT initiatives, including Green IT, require financial inputs to impart visibility and accountability to the decision making process. For instance, an organisation may desire to be a leader in environmental change but its ambition may be unattainable if its funding plan does not reflect the high disposal cost of old equipment. In another scenario, an IT department, in its zest to improve its environmental performance, may overinvest in "energy-efficient" hardware without prior consultation with the user and customer. This may lead to a situation of excess storage or processing capacity that does not generate value for the organisation. 


\begin{tabular}{|c|c|c|c|c|}
\hline ITSM Processes/Guidelines & & 品 & & 西 \\
\hline $\begin{array}{l}\text { Financial Management } \\
\text { Regulatory and environmental-related planning should get its } \\
\text { triggers from within the business. However, Financial } \\
\text { Management should apply the proper financial inputs to the } \\
\text { related services value, whether cost based or value based. } \\
\text { (Section 5.1.2.5) }\end{array}$ & $\mathbf{X}$ & $\mathbf{X}$ & $\mathbf{X}$ & $\mathbf{X}$ \\
\hline $\begin{array}{l}\text { Demand Management } \\
\text { Excess capacity generates cost without creating value that } \\
\text { provides a basis for cost recovery. Customers are reluctant to } \\
\text { pay for idle capacity unless it has value for them. (Section } \\
5.5 .1 \text { ) }\end{array}$ & $\mathbf{X}$ & $\mathbf{X}$ & $\mathbf{X}$ & \\
\hline
\end{tabular}

Table 2. Green IT Guidelines in Service Strategy (OGC 2007d)

The Service Design process, which is concerned with the design of appropriate and innovative IT services, has a number of areas that are extremely pertinent to Green IT as listed in Table 3. The Environmental Architectures and Standards guidelines stipulate that there should be an environmental policy governing the location and use of equipment in data centres. Such policy should reflect important equipment attributes such as room temperature, power distribution, lighting and even air quality, as they involve the consumption of electrical power and therefore are of concern to Green IT.

Both Availability Management and Capacity Management address the optimum availability and utilization of the IT infrastructure to provide cost-effective IT services at agreed service levels. There are various Green IT strategies that organisations can consider to meet these goals and they include the use of data centre, storage and client-device optimization software and adoption of the virtualization approach. In Service Level Management, IT organisations are required to meet agreed service levels through the proactive prevention of service failures and reduction of service risks. These may be achieved through the upgrade of existing hardware to newer and more energy-efficient technology and undertaking tuning activities to make more efficient use of existing IT resources. In Supplier Management organisations can mandate their suppliers to meet certain Green IT policies through appropriate contract negotiation.

Table 4 shows that both Release and Deployment Management, and Service Asset and Configuration Management in Service Transition are relevant to Green IT. Release and Deployment Management deal with the decommissioning and retirement of out-of-data and energy-inefficient systems, including peripheral equipment such as cooling systems, and their replacement with more efficient alternatives. The disposal of equipment in accordance with environmental policies and procedures in the organisation should also be considered. Service Asset and Configuration Management provide information that facilitates control over all IT assets in the organisation. The information is crucial to the formulation of appropriate Green IT decisions, such as consolidation of servers, virtualization, replacement and reuse, and retirement of these assets. 


\begin{tabular}{|c|c|c|c|c|}
\hline ITSM Processes/Guidelines & 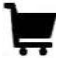 & 最 & $8:$ & 而 \\
\hline $\begin{array}{l}\text { Environmental Architectures \& Standards } \\
\text { Every organization should produce an environmental policy for equipment } \\
\text { location, with minimum agreed standards for particular concentrations of } \\
\text { equipment ... Building/site ... Major equipment room ... Major data centres } \\
\ldots \text {. Regional data centres and major equipment centres ... Server or network } \\
\text { equipment rooms ... Office environments. (Appendix E: Environmental } \\
\text { architectures and standards) }\end{array}$ & & & $\mathbf{X}$ & \\
\hline $\begin{array}{l}\text { Availability Management } \\
\text { A key activity for Availability Management is continually to look at } \\
\text { opportunities to optimize the availability of the IT infrastructure in } \\
\text { conjunction with Continual Service Improvement activities ... The } \\
\text { optimization approach is a sensible first step to delivering better value for } \\
\text { money. (Section 4.4.5.2) }\end{array}$ & & $\mathbf{X}$ & $\mathbf{X}$ & \\
\hline $\begin{array}{l}\text { Capacity Management } \\
\text { The main objective of Component Capacity Management is to identify and } \\
\text { understand the performance, capacity and utilization of each of the individual } \\
\text { components within the technology used to support the IT services ... This } \\
\text { ensures the optimum use of the current hardware and software resources in } \\
\text { order to achieve and maintain the agreed service level. (Section 4.3.5.3) }\end{array}$ & & $\mathbf{X}$ & $\mathbf{X}$ & \\
\hline $\begin{array}{l}\text { Service Level Management } \\
\text { Service Level Management should include ... proactive prevention of service } \\
\text { failures, reduction of service risks and improvement in the quality of service, } \\
\text { in conjunction with all other processes. (Section 4.2.2) }\end{array}$ & & $\mathbf{X}$ & $\mathbf{X}$ & $\mathbf{X}$ \\
\hline $\begin{array}{l}\text { Supplier Management } \\
\text { IT Supplier Management often has to comply with organizational or } \\
\text { corporate standards, guidelines and requirements, particularly those of } \\
\text { corporate legal, finance and purchasing. (Section 4.7.2) }\end{array}$ & $\mathbf{X}$ & & & \\
\hline
\end{tabular}

Table 3. Green IT Guidelines in Service Design (OGC 2007b)

\begin{tabular}{|c|c|c|c|c|}
\hline ITSM Processes/Guidelines & & 昌 & & 间 \\
\hline $\begin{array}{l}\text { Release \& Deployment Management } \\
\text { Some specific aspects need to be considered for decommissioning and } \\
\text { retiring services and service assets ... disposing of equipment according to } \\
\text { environmental policies and procedures. (Section 4.4.5.6) }\end{array}$ & & & & $\mathbf{X}$ \\
\hline $\begin{array}{l}\text { Service Asset \& Configuration Management } \\
\text { Configuration Management ... enables other processes to access valuable } \\
\text { information, e.g.: optimize asset utilization and costs ... consolidate data } \\
\text { centres, reduce variations and re-use assets. (Section } 4.3 .4 .2 \text { ) }\end{array}$ & $\mathbf{X}$ & $\mathbf{X}$ & $\mathbf{X}$ & $\mathbf{X}$ \\
\hline
\end{tabular}

Table 4. Green IT Guidelines in Service Transition (OGC 2007e) 


\begin{tabular}{|c|c|c|c|c|}
\hline ITSM Processes/Guidelines & ?ִ & 昌 & 8 & 更 \\
\hline $\begin{array}{l}\text { Server Management \& Support } \\
\text { The procedures and activities which must be undertaken by the Server } \\
\text { Team(s) or department(s) include ... procurement advice on the selection, } \\
\text { sizing, procurement and usage of servers and related utility software ... } \\
\text { definition and management of virtual servers ... provide information and } \\
\text { assistance to Capacity Management to help achieve optimum throughout, } \\
\text { utilization and performance from available servers ... Decommissioning and } \\
\text { disposal of old server equipment. (Section 5.4) }\end{array}$ & $\mathbf{X}$ & $\mathbf{X}$ & $\mathbf{X}$ & $\mathbf{X}$ \\
\hline $\begin{array}{l}\text { Facilities Management } \\
\ldots \text { key activity of Facilities Management is to manage the utilization of } \\
\text { power ... as natural resources become scarcer and expensive, more attention } \\
\text { is being focused on techniques to manage utilization more responsibly. } \\
\text { (Appendix E: Detailed description of Facilities Management) }\end{array}$ & & & $\mathbf{X}$ & \\
\hline
\end{tabular}

Table 5. Green IT Guidelines in Service Operation (OGC 2007c)

Server Management and Support, and Facilities Management are two sets of guidelines in Service Operations that are directed at the management of two major components in the data centre: server hardware which provides crucial services, such as application hosting and data storage, and physical facilities. Server Management and Support outlines procedures and activities associated with the lifecycle of the server ranging from procurement, management of virtual servers, utilization and performance of servers to the decommissioning and disposal of old servers. Most of these procedures and activities are consistent with Green IT as shown in Table 5. Facilities Management, on the other hand, addresses Green IT topics such as power management, management of environmental cooling systems, equipment maintenance and maintenance contract. In the guidelines ITILv3 acknowledges the increasing cost of power and need for power management techniques.

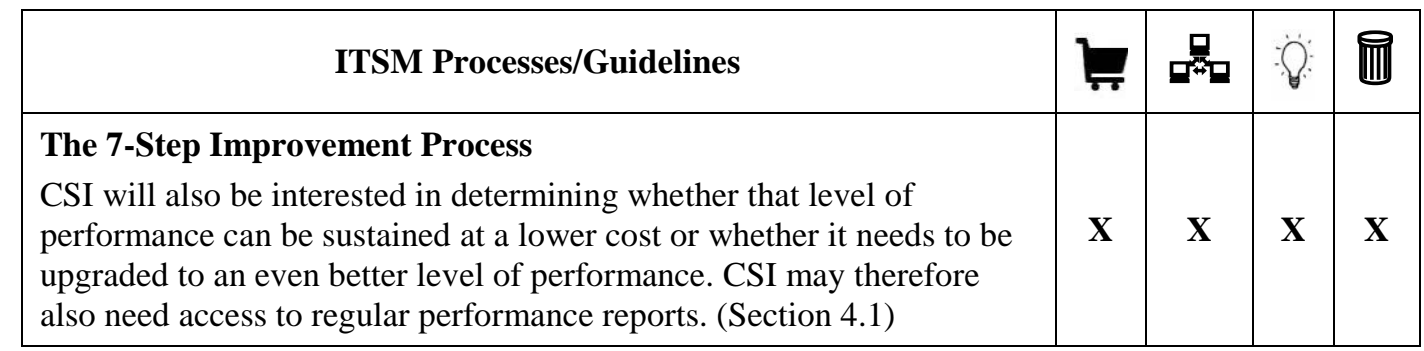

Table 6. Green IT Guidelines in Continual Service Improvement (OGC 2007a)

Continual Service Improvement (CSI) in ITILv3 is concerned with maintaining value for the organisation through continual evaluation and improvement of the IT services. In effect, as Table 6 shows, CSI focuses on improving the effectiveness and efficiency of the IT infrastructure as well as the cost effectiveness of the data centre operation. The 7-step improvement process prescribed in CSI is equally applicable to Green IT as it is to ITSM. In fact, the seven steps can be mapped to the AGIMO Green IT elements to drive Green IT initiatives, as depicted in Table 7. 


\begin{tabular}{|l|l|}
\hline \multicolumn{1}{|c|}{ The 7-Step Improvement Process } & \multicolumn{1}{c|}{ AGIMO Green IT Elements } \\
\hline Step 1 - Define what you should measure & 1. Use and operation of ICT products/services \\
Step 2 - Define what you can measure & \\
Step 3 - Gather the data & \\
Step 4 - Process the data & \\
Step 5 - Analyze the data & \\
\hline Step 6-Present and use the information & 4. Environmental reporting requirements \\
\hline Step 7 - Implement corrective action & $\begin{array}{l}\text { 2. Procurement of ICT products and services } \\
\text { 3. Re-use, recycling and disposal of ICT } \\
\text { products and services }\end{array}$ \\
\hline
\end{tabular}

Table 7. Comparison of ITILv3 7-step improvement process and AGIMO elements

Although ITILv3 does not make explicit mention of Green IT, it is nonetheless clear from the five publications (Service Strategy, Service Design, Service Transition, Service Operation and Continual Service Improvement) that the framework can contribute to helping IT Service Managers achieve Green IT outcomes. Service Strategy ensures that the Green IT solutions are not created in isolation from the over-arching strategy and culture of the organisation. Service Design deals with the architectures, processes and capabilities of the new Green options while Service Transition focuses on their transition into the live environment. Service Operations ensures that the implemented Green IT solutions continue to deliver agreed levels of service to users and customers. The encompassing Continual Service Improvement book provides guidelines on maintaining or enhancing the value of the Green investments.

\section{SURVEY}

Over the past five years, the authors have conducted extensive research with itSMF Australia. The focus of the research to date has been on the adoption and implementation of ITSM, in particular ITIL (Cater-Steel 2009; Cater-Steel \& Toleman 2007; Tan, Cater-Steel \& Toleman 2009). We are unable to report here the full results of this work. Rather, we intend to only address issues pertinent to Green IT.

The survey questionnaire used annually at itSMF conferences since 2005 was adapted to include a section with eight questions on adoption of Green IT initiatives. The questions listed in Table 8 were derived from the literature review and content analysis of the ITIL books.

At the itSMF Australia Conference in Sydney in 2009, each delegate was provided with a questionnaire in their conference pack and requested to complete it at the conference. In total, 65 completed questionnaires were returned. These were scanned by itSMF staff using an optical mark recognition (OMR) system. The resulting Excel file was checked against the survey forms and used to perform statistical analysis. The survey responses were anonymous, but respondents were invited to record their name, address and email address if they wished to receive a summary report of the results of the survey.

\section{Demographics}

The survey respondents represented all Australian states with the exception of the Northern Territory. There was strong support from Victoria (26\%) and the Australian Capital Territory (23\%) ahead of Queensland (15\%) and New South Wales (14\%). Although six percent of respondents were CIOs or IT managers, most of the respondents were managers in the area of ITSM: process managers $(28 \%)$, service managers (8\%), service desk managers (4\%), and operations managers $(4 \%)$. The industries 
reported were dominated by government, administration and defence $(28 \%)$, followed by education $(11 \%)$, property, business and IT services (10\%), finance and insurance (5\%) and manufacturing, construction and mining (5\%). Most of the respondents represented large organisations: 28 percent reported an annual turnover or budget of more than $\$ 500$ million; 30 percent employed more than 5000 staff; and 25 percent have in excess of 400 IT staff. All respondents indicated that their organisation had adopted the ITILv3 framework.

\begin{tabular}{|l|l|}
\hline \multicolumn{1}{|c|}{$\begin{array}{c}\text { ITIL Lifecycle } \\
\text { Stage }\end{array}$} & \multicolumn{1}{c|}{ Survey Questions } \\
\hline Service Strategy & 1. Does your organisation have a Green-IT policy? \\
\hline Service Design & $\begin{array}{c}\text { 2. Do you ensure that your suppliers meet Green criteria and their } \\
\text { products support the business's Green objectives? }\end{array}$ \\
\cline { 2 - 3 } & 3. Have you included Green IT goals in the defined service levels? \\
\cline { 2 - 3 } & $\begin{array}{l}\text { 4. Is your organisation shifting towards virtualisation to reduce the } \\
\text { number of servers? }\end{array}$ \\
\hline Service Transition & $\begin{array}{l}\text { No relevant questions. Role of Service Transition is to implement the } \\
\text { services required by the business. }\end{array}$ \\
\hline Service Operation & $\begin{array}{l}\text { 5. Do you have a process for analysing power consumption of IT } \\
\text { equipment? }\end{array}$ \\
\cline { 2 - 3 } & $\begin{array}{l}\text { 6. Do you have a policy to dispose of IT waste in the most } \\
\text { environmentally friendly way possible? }\end{array}$ \\
\cline { 2 - 3 } & $\begin{array}{l}\text { 7. Do you track cost-savings associated with Green tactics and } \\
\text { strategies? }\end{array}$ \\
\hline $\begin{array}{l}\text { Continual Service } \\
\text { Improvement }\end{array}$ & $\begin{array}{l}\text { 8. Does your CMDB/CMS store information that helps drive Green } \\
\text { goals? }\end{array}$ \\
\hline
\end{tabular}

Table 8. Survey Questions Derived from Content Analysis of ITILv3

\section{Green IT Progress}

A six-point scale was used to measure the status of implementation: no plans, starting, partially, largely, fully and don't know. For ease of reporting, the responses for starting, partially and largely implemented were consolidated as 'in progress'. In Table 9, the questions are listed in decreasing order of positive responses.

The question revealing the most mature level of implementation related to waste disposal with 93 percent of respondents indicating a policy was at some stage of implementation to dispose of IT wastes in the most environmentally friendly way possible. In terms of Service Strategy, two thirds of respondents reported that their organisation had a Green IT policy but it was fully implemented in only two organisations. The question relating to the ability of the configuration management database (CMDB) and configuration management system (CMS) to drive Green goals also drew a positive response from two thirds of the respondents. Power consumption analysis of IT equipment is on the agenda for more than half the respondents.

Almost half of the respondents were taking action to include Green IT goals in service level agreements. The remaining questions did not evoke positive responses. A high proportion (38\%) did not know if Green IT cost savings were being tracked. In terms of procurement, more than one third of respondents had no plans to ensure suppliers meet Green criteria. The reaction of respondents to the question on server virtualisation was surprising: 62 percent of respondents did not answer this question. 


\begin{tabular}{|l|c|c|c|c|c|}
\hline \multicolumn{1}{|c|}{ Survey Question } & \multicolumn{4}{c|}{ Status of implementation } \\
\cline { 2 - 6 } & $\begin{array}{c}\text { No } \\
\text { plans }\end{array}$ & $\begin{array}{c}\text { In } \\
\text { progress }\end{array}$ & $\begin{array}{c}\text { Fully } \\
\text { implemented }\end{array}$ & $\begin{array}{c}\text { Don't } \\
\text { know }\end{array}$ & Blank \\
\hline $\begin{array}{l}\text { Q6. Do you have a policy to dispose of IT } \\
\text { waste in the most environmentally friendly } \\
\text { way possible? }\end{array}$ & 1 & 61 & 5 & 3 & 0 \\
\hline $\begin{array}{l}\text { Q1. Does your organisation have a Green-IT } \\
\text { policy? }\end{array}$ & 8 & 44 & 2 & 12 & 1 \\
\hline $\begin{array}{l}\text { Q8. Does your CMDB/CMS store information } \\
\text { that helps drive Green goals? }\end{array}$ & 4 & 43 & 3 & 18 & 0 \\
\hline $\begin{array}{l}\text { Q5. Do you have a process for analysing } \\
\text { power consumption of IT equipment? }\end{array}$ & 9 & 38 & 4 & 18 & 0 \\
\hline $\begin{array}{l}\text { Q3. Have you included Green IT goals in the } \\
\text { defined service levels? }\end{array}$ & 15 & 30 & 1 & 17 & 3 \\
\hline $\begin{array}{l}\text { Q7. Do you track cost-savings associated with } \\
\text { Green tactics and strategies? }\end{array}$ & 14 & 25 & 3 & 25 & 1 \\
\hline $\begin{array}{l}\text { Q2. Do you ensure that your suppliers meet } \\
\text { Green criteria and their products support the } \\
\text { business's Green objectives? }\end{array}$ & 24 & 18 & 1 & 22 & 1 \\
\hline $\begin{array}{l}\text { Q4. Is your organisation shifting towards } \\
\text { virtualisation to reduce the number of servers? }\end{array}$ & 3 & 2 & 0 & 20 & 40 \\
\hline
\end{tabular}

Table 9. Responses to Green IT Questions (65 responses)

In summary, the itSMF survey reported a large variation regarding efforts towards implementation of IT Green initiatives. Although a handful of organisations had fully implemented most of the initiatives listed, at the other extreme a larger proportion did not know if their organisation was undertaking these Green IT activities.

\section{DISCUSSION}

Although the content analysis of the ITIL books identified various references to practices which could support Green IT, the ITIL framework is deficient in describing explicit practices to manage IT services that will have minimal impact on the global environment. For example, in service design, under environmental architectures and standards, organisations should have an environmental policy but the focus is on the internal environment in terms of temperature, lighting etc. There is no advice provided about consideration of the external environment, for example carbon dioxide emission effects on global warming. In service operations, although server virtualisation is encouraged and disposal of old equipment is mentioned, the benefits in terms of the environment are not articulated. This sentiment echoes Firth (2008) who commented that ITILv3 fails to address this decade's greatest corporate challenge, the environment, and therefore represents a missed opportunity.

The ITILv3 framework is based on a service lifecycle model. To further understand the relationship between ITSM and Green IT, Erek et al.'s Value Chain of IS Management model (Figure 2) is considered as a Green IT lifecycle model.

The Value Chain of IS Management model is useful as it has been applied by Erek et al. (2009) to clarify the relationship between Green IT and ITSM and provided insights as to how the service 
lifecycle can be applied to Green IT initiatives. Mapping the ITIL books to this model reveals that they are complementary in structure as shown in Table 10.

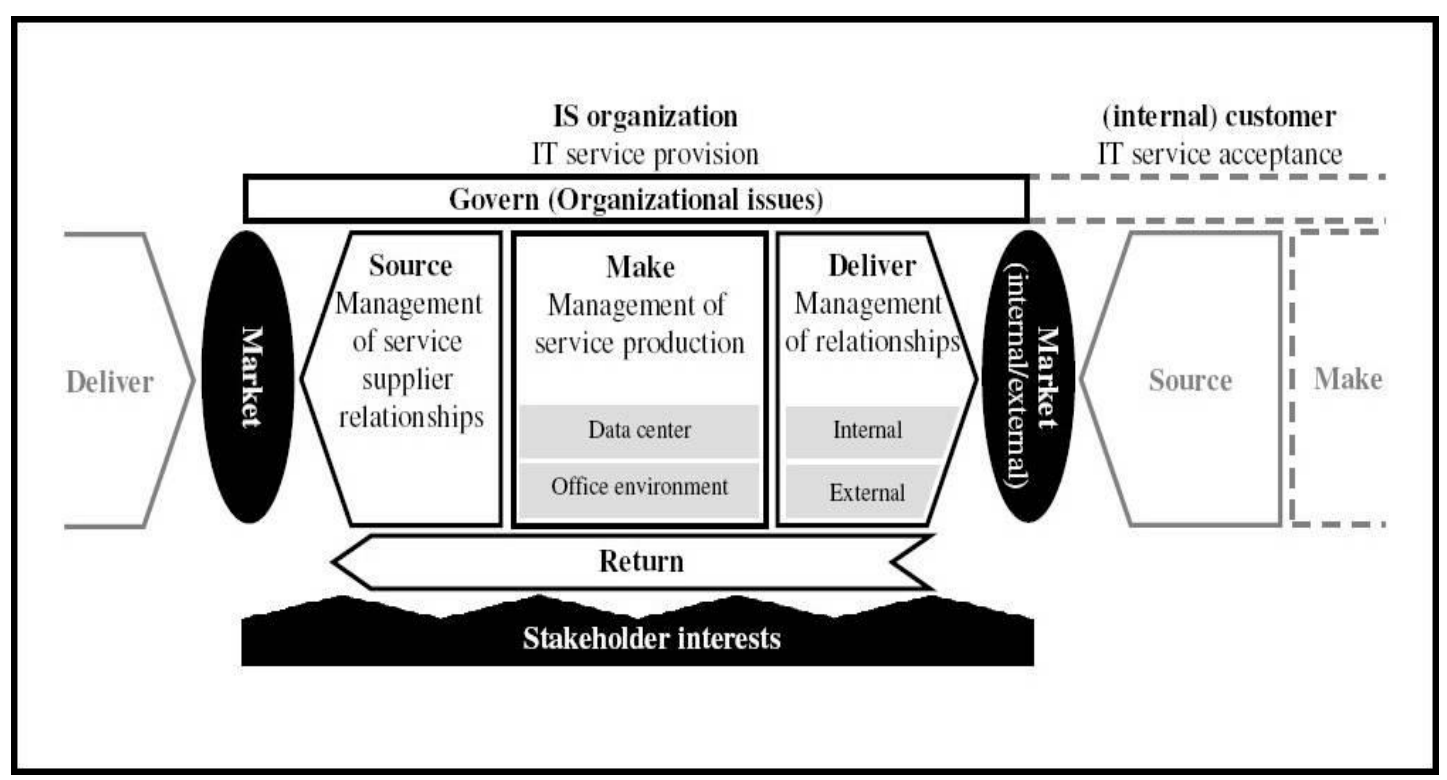

Figure 2. Value Chain of IS Management (Erek et al. 2009, p. 3)

\begin{tabular}{|l|c|c|c|c|c|}
\hline \multirow{2}{*}{ ITIL Lifecycle Stages } & \multicolumn{5}{|c|}{ Value Chain of IS Products \& Services } \\
\cline { 2 - 6 } & Govern & Source & Make & Deliver & Return \\
\hline Service Strategy & $\mathrm{X}$ & & & & \\
\hline Service Design & & $\mathrm{X}$ & $\mathrm{X}$ & & \\
\hline Service Transition & & & $\mathrm{X}$ & & \\
\hline Service Operations & & & & $\mathrm{X}$ & $\mathrm{X}$ \\
\hline $\begin{array}{l}\text { Continuous Service } \\
\text { Improvement }\end{array}$ & & $\mathrm{X}$ & $\mathrm{X}$ & $\mathrm{X}$ & $\mathrm{X}$ \\
\hline
\end{tabular}

Table 10. ITIL Lifecycle Stages Mapped to IS Value Chain

Relating the survey results to the preliminary theoretical framework (Figure 1), only two of the four proposed initiatives were actively pursued by respondents: decommissioning/disposal of unused/obsolete equipment, and power consumption analysis. There was no strong evidence that suppliers or products were monitored and the question regarding consolidation of resources was avoided by most of the respondents. The itSMF survey indicated that most organisations had a Green IT policy, recognised the importance of controlling the disposal of ICT waste, and recorded useful information in their CMDB.

However, it is surprising that a large proportion of the survey respondents did not know if their organisation is shifting towards virtualisation to reduce the number of servers. Server consolidation and virtualisation are popular topics in the practitioner press, online forums and vendor seminars. It may be the case that in the large organisations represented by the survey the service management staff are not fully informed of their data centre strategies.

One of the premises in ITIL is that all IT Service Providers - either as in-house departments or external vendors - need a service strategy that is based on the recognition of the existence of 
competition. Clearly, the existence of a Green IT service strategy aimed at the implementation of Green IT practices and Green IT technologies would be viewed favourably by customers and may provide a competitive advantage. In addition, a cost advantage may be realised as ITIL emphasizes the optimum use of the physical facilities at the data centre and the implementation of a continual improvement program to raise the effectiveness and efficiency of various IT services and the underlying applications. The supplier management process in ITIL further ensures that suppliers adhere to the Green IT policies that are built into the contracts during prior negotiation.

\section{CONCLUSION}

This paper has taken a pragmatic approach to explore the relationship between IT Service Management (ITSM) and Green IT. Although the analysis of the ITIL books clearly demonstrates that ITIL provides limited guidance to support Green IT programs, it does confirm Blanke's view (2009) that Green IT and ITSM share common goals, such as operational efficiencies and metrics-based improvements. Unfortunately the relatively small number of survey responses limits confidence in generalising the results. Nevertheless the survey findings indicate that most of the IT Service Managers are aware of the importance of Green IT procurement, improving efficiency and controlling waste disposal, but not server consolidation. The extent to which Green IT policies and procedures have been implemented varied substantially across the 65 organisations surveyed. Existing processes and supporting ITSM tools (such as CMDB) can easily be adapted to support Green IT initiatives, and as indicated by the survey responses, this is starting to happen. ITIL provides a framework based on a life-cycle view of IT services to ensure services are integrated with the organisations strategy. As organisations adopt best practice frameworks such as ITIL, the IT department or IT service provider and the organisation can work together more effectively to determine how the company can save money, be Green, and still achieve the goals of the business.

Based on the review of the literature, and analysis of the ITIL books and survey data, the following recommendations are made:

1. CIOs and IT Service managers need to enquire about Green initiatives in their organisation at the Corporate level and engage with the process. They can use the ITIL 7-step method to assess the current situation, develop an action plan and then achieve Green credentials for the IT department. In particular, IT Service managers must consider how to use existing technologies, and work to incorporate new ones into their organisation's Green IT policies and practices. To do this, they need to put pressure on their IT managers and CIOs to move Green benefits to the forefront of their strategic thinking.

2. As climate change is a global and complex issue, managers need to invest time and funds in training to improve their knowledge. For example, the British Computer Society offers a Green IT certificate which covers Green IT regulations, legislation and policy, identification and base-lining of current Green IT credentials, and advice on how to move forward in delivering Greener IT (BCS 2009).

3. IT Service managers need to keep up to date with legislation as well as maintaining awareness of Green initiatives undertaken by their suppliers and competitors. Industry associations such as the itSMF and the Australian Computer Society (ACS) could play a stronger role by promoting Green IT awareness and the Green aspects of ITIL.

4. Best practice in Green IT is evolving and needs to be better distilled and articulated in the ITIL and ISO 20000 standards. The authors of the ITIL resources, under the direction of OGC should include more specific guidelines related to Green IT in the next revision of the ITIL publications. Members of the standards working group responsible for ISO/IEC 20000 need to 
include Green IT guidance in future revisions of the international standard for IT Service Management.

This study has a number of limitations. The small number of responses precluded correlation analysis of associations between Green IT initiative implementation and demographics such as organisation size, industry sector and also maturity of ITIL processes. We deliberately took a pragmatic approach by commencing with the ITIL books as representing best practice in ITSM. In contrast, a theoretical approach could be considered to incorporate recently developed models such as Schmidt et al.'s (2009) procedural model for sustainable information systems management. Due to the focus on ITSM, the study did not recognise the key role IT can play in reducing the environmental impact of organisations and making their key processes more sustainable.

As far as articulating a research agenda for future work, the authors intend to undertake a more detailed analysis of the current shortcomings in ITILv3 and ISO/IEC 20000 standard in relation to the environmentally safe delivery and management of IT in the organisation. It is proposed to map ITILv3 to the Value Chain of IS Management model. Earlier work by Zarnekow et al. (2006) provided valuable advice to IS managers by mapping the previous version of ITIL (v2) to the IIM model and highlighted deficiencies in the level of detail provided by ITILv2.

Following this analysis, the Green IT survey questions will be revised and extended for the itSMF 2011 conference survey, enabling a comparison of the 2009 and 2011 results to gauge the progress of organisations in implementing Green IT initiatives. To ensure a deeper understanding of the issues surrounding Green IT in ITSM, we also plan to conduct interviews with IT Service managers to explore the challenges they experience in adopting and implementing Green IT initiatives.

\section{ACKNOWLEDGEMENTS}

The authors would like to acknowledge the ongoing support from the directors and staff of itSMF Australia and thank Prof Mark Toleman for reviewing the questionnaire.

\section{REFERENCES}

ACS 2007, Audit of Carbon Emissions resulting from ICT usage by Australia Business, Australian Computer Society.

AGIMO 2007, Better Practice Checklist: Managing the environmental impact of information and communications technology (ICT), Australian Government Information Management Office, Department of Finance and Deregulation.

Alavi, M \& Leidner, DE 2001, 'Knowledge Management and Knowledge Management Systems: Conceptual Foundations and Research Issues', MIS Quarterly, vol. 25, no. 1, pp. 107-36.

BCS 2009, ISEB Foundation Certificate in Green IT, BCS: the Chartered Institute for IT, viewed 15 November 2009, <http://www.bcs.org/server.php?show=nav.10479>.

Benbasat, I, Goldstein, DK \& Mead, M 1987, 'The Case Research Strategy in Studies of Information Systems', MIS Quarterly, vol.11, no. 3. pp. 369-87.

Blanke, MS 2009, Green IT Service Management: An Overview of How a Service Management Framework Can Contribute to Your Green Goals, OwlPoint, Hillsborough, NJ.

Brown, D, Dillard, J \& Marshall, R 2005, 'Strategically informed, environmentally conscious information requirements for accounting information systems', Journal of Information Systems, vol. 19, no. 2, pp. 79-103.

BSI 2008, PAS 2050 - Assessing the life cycle greenhouse gas emissions of goods and services. 
Butler, T \& Daly, M 2009, 'Environmental responsibility and Green IT: An institutional perspective', paper presented to In 17th European Conference on Information Systems Verona, Italy.

Capra, E. \& Merlo, F 2009, 'Green IT: Everything Starts from the Software', paper presented to ECIS, Verona, Italy, June 8-10.

Cater-Steel, AP 2009, 'IT Service Departments Struggle to Adopt a Service-Oriented Philosophy ', International Journal of Information Systems in the Service Sector, vol. 1, no. 2, pp. 69-77.

Cater-Steel, AP \& Toleman, M 2007, 'Education for IT Service Management', International Journal of IT Standards and Standardization Research, vol. 5, no. 2, pp. 27-42.

Chen, A, Boudreau, M \& Watson, RT 2008, 'Information Systems and ecological sustainability', Journal of Systems and Information Technology, Sustainability and Information Systems, vol. 10, no. 3, pp. 186-201.

Cherrington, C \& Greenway, D 2008, Green ITIL, Capgemini, Woking, Surrey.

Cole, D 2003, 'Energy Consumption and Personal Computers', in R Kuehr \& E Williams (eds), Computers and the Environment: Understanding and Managing Their Impacts, Kluwer Academic Publishers and United Nations University, pp. 131-59.

COMLAW 2009, Hazardous Waste (Regulation of Exports and Imports) Act 1989 (Amended 2009), Australia.

EC 2008, Directive 2008/34/EC on waste electrical and electronic equipment (WEEE), European Community.

Elliott, S 2007, 'Environmentally sustainable ICT: a critical topic for IS research?' paper presented to PACIS, Auckland, NZ, 4-7 July.

Elliott, S \& Binney, D 2008, 'Environmentally sustainable ICT: developing corporate capabilities and an industry relevant IS research agenda', paper presented to PACIS, Suzhou, China, 4-7 July.

EPA 2009, Energy Star, US Environmental Protection Agency, viewed 12 December 2009, <http://www.energystar.gov/>.

Erek, K, Schmidt, N-H, Zarnekow, R \& Kolbe, LM 2009, 'Sustainability in Information Systems Assessment of Current Practices in IS Organizations', paper presented to AMCIS, San Francisco.

Firth, R 2008, 'How Green is ITIL', ITAdvisor, vol. 54, no. Summer.

Gartner 2007, Gartner Estimates ICT Industry Accounts for 2 Percent of Global CO2 Emissions, viewed 5 December 2009, <http://www.gartner.com/it/page.jsp?id=503867>.

GEC 2006, EPEAT: Green Electronics Made Easy, viewed 5 December 2009, $<$ http://www.epeat.net/>.

Gershon, P 2008, Review of the Australian Government's Use of Information and Communication Technology, Commonwealth of Australia.

Ghose, A, Hoesch-Klohe, K, Hinsche, L \& Le, L-S 2009, 'Green Business Process Management: a Research Agenda', Australasian Journal of Information Systems, vol. 16, no. 2, pp. 103-17.

Hart, SL 1997, 'Beyond Greening: Strategies for a Sustainable World', Harvard Business Review, vol. 75, no. 1 , pp. 66-76.

Hoover, JN 2009, 'Obama Orders Federal IT to Get Greener ', InformationWeek Oct 6th.

Huang, AH 2009, 'A Model for Environmentally Sustainable Information Systems Development', Journal of Computer Information Systems, no. Summer, pp. 114-21.

ISO 2004, ISO 14001:2004 Environmental management systems - Requirements with guidance for use. 
itSMF 2009, Certified Organisations, viewed $10 \quad$ July 2009, <http://www.isoiec20000certification.com/lookuplist.asp?Type=9>.

itSMFI 2010, itSMF International: the IT Service Management Forum, viewed 14 May 2010, <http://www.itsmfi.org/content/about-itsmfi .

Knox, S \& Lull, PB 2009, The Next Wave of Green IT: IT's role in the future of enterprise sustainability, CFO Research Services \& Deloitte, Boston, MA.

Krippendorf, K 2004, Content analysis : an introduction to its methodology, 2 edn, Sage, Thousand Oaks, Calif.

Kuo, BN \& Dick, GN 2009, 'The Greening of Organisational IT: What Makes a Difference?' Australasian Journal of Information Systems, vol. 16, no. 2, pp. 81-92.

Maruster, LF, Faber, NR \& Peters, K 2008, 'Sustainable Information Systems: a Knowledge Perspective', Journal of Systems and Information Technology, vol. 10, no. 3, pp. 218-31.

Matthews, HS \& Matthews, DH 2003, 'Information Technology Products and the Environment', in R Kuehr \& E Williams (eds), Computers and the Environment: Understanding and Managing Their Impacts, Kluwer Academic Publishers and United Nations University, pp. 17-39.

Mines, C 2008, The Dawn of Green IT Services, Forrester.

Molla, A 2008, 'GITAM: A Model for the Acceptance of Green IT', paper presented to ACIS 2008, Christchurch, NZ.

---- 2009, 'The Reach and Richness of Green IT: A Principal Component Analysis', paper presented to ACIS 2009, Melbourne.

Molla, A, Pittayachawan, S, Corbitt, BJ \& Deng, H 2009, 'An International Comparison of Green IT Diffusion', International Journal of e-Business Management, vol. 3, no. 2, pp. 3-23.

Molla, A, Cooper, V, Corbitt, BJ, Deng, H, Peszynski, KJ, Pittayachawan, S \& Teoh, SY 2008, 'Ereadiness to G-readiness: developing a green information technology readiness framework', paper presented to ACIS 2008, Christchurch, NZ.

Murugesan, S 2008, 'Harnessing Green IT: Principles and Practices', IT Pro (IEEE Computer Society), pp. 24-33.

OGC 2007a, Continual Service Improvement, TSO for the Office of Government Commerce, London.

---- 2007b, Service Design, TSO for the Office of Government Commerce, London.

---- 2007c, Service Operation, TSO for the Office of Government Commerce, London.

---- 2007d, Service Strategy, TSO for the Office of Government Commerce, London.

---- 2007e, Service Transition, TSO for the Office of Government Commerce, London.

Poniatowski, M 2009, Foundations of Green IT: Consolidation, Virtualization, Efficiency, and ROI in the Data Center, Prentice Hall, Upper Saddle River, NJ, USA.

Potter, K 2008, Green IT Services as a Catalyst for Cost Optimization, Gartner.

Saied, M \& Velaquez, GT 2003, 'PCs and Consumers: a Look at Green Demand, Use, and Disposal', in R Kuehr \& E Williams (eds), Computers and the Environment: Understanding and Managing Their Impacts, Kluwer Academic Publishers and United Nations University, pp. 161-81.

Sarkar, PK \& Young, LW 2009, 'Managerial Attitudes towards Green IT: an Explorative Study of Policy Drivers', paper presented to PACIS 2009.

Scheerer, B \& Somashekar, S 2009, The Role of IT Management Software in the Greening of IT, CA. 
Schmidt, N-H, Erek, K, Kolbe, LM \& Zarnekow, R 2009, Towards a Procedural Model for Sustainable Information Systems Management', paper presented to HICSS, Hawaii.

Scott, WR 2000, Institutions and organizations, Sage Publications, Thousand Oaks, CA.

Tan, W, Cater-Steel, A \& Toleman, M 2009, 'Implementing IT service management: a case study focussing on critical success factors', Journal of Computer Information Systems (JCIS), vol. 50, no. 2, pp. 1-12.

Velte, T, Velte, A \& Elsenpeter, RC 2008, Green IT: Reduce Your Information System's Environmental Impact While Adding to the Bottom Line McGraw-Hill Companies.

Walker, HL, Gough, S, Bakker, EF, Knight, LA \& McBain, D 2009, 'Greening Operations Management: An Online Sustainable Procurement Course for Practitioners', Journal of Management Education, vol. 33, no. 3, pp. 348-71.

Watson, R, Boudreau, M-C, Chen, A \& Huber, M 2007, 'Green IS: Building Sustainable Business Practices', in R Watson (ed.), Information Systems: A Global Text, Global Text Project.

Zarnekow, R, Brenner, W \& Pilgram, U 2006, Integrated Information Management: Applying Successful Industrial Concepts in IT, Springer, Berlin. 